\title{
Vorwort zur 2. Auflage
}

Seit Erscheinen der 1. Auflage sind 26 Jahre vergangen. Die Anlage in Investmentfonds erfreut sich allgemeinen Interesses. Dieses weltweite Phänomen beschränkt sich nicht auf die Industrienationen, sondern hat auch die jungen Märkte (,emerging markets“) erfaßt. Privatpersonen (über Publikumsfonds), Institutionen und Unternehmen (insbes. über Spezialfonds) bedienen sich in gleicher Weise der vielfältigen Anlagemöglichkeiten und Verwaltungsvorteile der Investmentanlage. Das Gesetz über Kapitalanlagegesellschaften (KAGG), die maßgebende Rechtsgrundlage für die Investmentfonds in Deutschland, und das Auslandinvestment-Gesetz (AuslInvestmG), das den öffentlichen Vertrieb ausländischer Investmentanteile und die steuerliche Behandlung ausländischer Investmenterträge regelt, sind mehrfach geändert worden. Wesentliche Änderungen ergaben sich aus der Körperschaftsteuerreform 1976, dem (1.) Finanzmarktförderungsgesetz von 1990 mit der Anpassung an die OGAW-Richtlinie (Richtlinie 85/611/EWG), den Vertriebserleichterungen für EG-Investmentanteile, dem Zugang zu den Derivaten und der Deregulierung für Spezialfonds, dem Zinsabschlaggesetz von 1992, dem Mißbrauchsbekämpfungs- und Steuerbereinigungsgesetz von 1993 mit der Einführung der Besteuerung des Zwischengewinns und dem 2. Finanzmarktförderungsgesetz von 1994 mit Erweiterungen der Anlagemöglichkeiten im derivativen Geschäft, der Zulassung von Geldmarktfonds und der Einbeziehung ausländischer Geldmarktfonds in das AuslInvestmG. Durch das Zweite Vermögensbeteiligungsgesetz von 1986 ist das KAGG um Vorschriften für Beteiligungs-Sondervermögen erweitert worden, deren praktische Anwendung jedoch noch aussteht.

Die Vielzahl von Gesetzesänderungen erforderte eine umfassende Revision des Kommentars. Um den Umgang mit den Erläuterungen zu erleichtern, wurde ein Randnummernsystem eingeführt. Dem Kommentar ist vorangestellt eine allgemeine Einleitung, die in Teil I Begriffe des Investmentsparens erläutert, in Teil II einen Überblick über die Europäischen Harmonisierungsbestrebungen gibt und in Teil III Grundinformationen zur Situation der Investmentfonds (UCITS/Mutual Funds) in den Mitgliedstaaten der EG/Vertragsstaaten des EWR sowie in der Schweiz, in Japan und in den USA vermittelt.

Die Neufassung des Kommentars ist das Ergebnis einer Vielzahl von Gesprächen mit der Aufsichtsbehörde, mit Fachkollegen und Wirtschaftsprüfern. Die bis Ende 1995 veröffentlichten Schreiben des Bundesaufsichtsamtes für das Kreditwesen und der Finanzverwaltung sowie die wesentliche Literatur sind berücksichtigt. Ich nehme die Gelegenheit wahr, allen, die mich bei der mehrjährigen Vorbereitung mit ihren Anregungen unterstützt haben, zu danken. Stellvertretend gilt ein besonderer Dank meiner Sekretärin, Frau Mittné, die sich mit großer Sorgfalt und Geduld meinem wiederholt geänderten Manuskript angenommen und die Reinschrift gefertigt hat. Mein Dank gilt auch dem Verlag Walter de Gruyter für die verlegerische Betreuung und die Bereitschaft, die bereits gesetzten Texte entsprechend den Gesetzesänderungen zu aktualisieren.

Köln, im Februar 1996

Jürgen Baur 